\title{
Merging teaching personal and social responsibility with sport education: A marriage made in heaven or hell?
}

\author{
Barrie Gordon - Victoria University of Wellington
}

\begin{abstract}
$T_{n}$ eaching Personal and Social Responsibility (TPSR) is a pedagogical approach to the teaching of physical education that has been developed with the intention of helping students to become more personally and socially responsible. One prominent model that appears to be almost a natural partner to TPSR within physical education is that of Sport Education. This article explores the teaching of TPSR and Sport Education as a merged model; it looks at the commonalities between the models that suggest teaching the two together will be successful, and at the tensions and problems that may arise when this occurs. The article concludes with suggestions for teachers contemplating teaching the merged model in their classroom practice.
\end{abstract}

\section{Introduction}

Teaching Personal and Social Responsibility (TPSR) is a pedagogical approach to the teaching of physical education that has been developed with the explicit intention of using the contexts of physical activity and sport to help students to become more personally and socially responsible (Hellison, 2003; Hellison \& Martinek, 2006). While TPSR is often associated with at-risk and/or under-served youth, it was initially developed for, and has a long history of being used in, the teaching of physical education (Gordon, 2007; Hellison, 2003).

TPSR has often been described as a pedagogical model, a designation that can lead teachers to believe that there is limited flexibility in the ways that TPSR can be implemented into their classrooms. This is not the intention of TPSR, which is a model that actively encourages teachers to be creative when attempting to find the most effective ways of meeting the needs of their students. Hellison et al. (2000) commented that:

Although the notion of using a model sometimes conjures up some rigid recipe to which we must adhere, we use the term model as ... having a theoretical-philosophical focus and a body of supporting evidence, as well as actually being in practice, not just some college professor's brainstorm. That theoretical-philosophical focus is, in a sense, a spirit, a "way of being", rather than a rigid formula, and leaders need to own and adapt it to fit their settings, students, and style. (pp. 44-45)
While a strong philosophical understanding gives the opportunity for flexibility in how TPSR is implemented, the degree of adherence to the framework that is necessary for it to remain under the umbrella of TPSR is an important question. It would generally be expected that teachers who are implementing TPSR would underpin their teaching with two important structures. The first of these is a series of five goals, often referred to as Levels of Responsibility, which are commonly observed via posters displayed in gymnasia or classrooms. These goals/levels are identified as (1) respect; (2) participation and effort; (3) self-direction; (4) caring; and (5) the transfer of learning around personal and social responsibility to other areas of students' lives.

Supporting students to achieve these goals/levels is a five stage teaching sequence that is used as the basis for coaching sessions or physical education classes. The first stage, counselling time, involves teachers deliberately spending time with individuals within their classes in order to develop positive relationships. The second stage, an awareness talk, is used to focus the students on the goals of TPSR. The third stage, activity time, relates to the physical activity part of the lesson. During this time it is important that the pedagogical approaches selected are appropriate for achieving both the goals of the physical education curriculum and those of TPSR. Towards the end of the lesson a group meeting occurs when the students, as a group, have the opportunity to discuss events that have 
occurred in class. The final stage of the lesson, individual reflection time, is time given for students to reflect on their own behaviour in relation to the goals/levels.

While acknowledging the framework and structure associated with TPSR, it is important to reiterate the importance of what Hellison described as a "way of being", a way of teaching and relating to students that demonstrates that the teacher understands the model at a fundamental level. As Hellison et al. (2000) commented, simply "Posting the responsibility levels on a gym wall does not necessarily mean that the spirit of the model is being practiced in this gym" (p. 44).

The above description of TPSR only offers a brief overview and readers who would like to gain further knowledge will find valuable additional information in a number of Hellison's publications (see for example Hellison, 2003; Hellison et al., 2000).

\section{TPSR and Sport Education}

For physical education teachers who are interested in exploring different contexts and ways in which to teach TPSR, one prominent model that appears to be almost a natural partner is Sport Education (Siedentop, 2002; Siedentop, Hastie, \& Van der Mars, 2004). Sport Education was introduced into physical education to allow students to experience the positive aspects of sporting culture and to "learn to distinguish between good sport and bad sport" (Siedentop et al., 2004, p. ix). Sport Education seeks to give students the opportunity to parallel as closely as possible the experiences of participating in a sports team throughout a full sporting season. After an initial selection process students are placed into teams in which they remain for the full season. Their programme includes practices, pre-season games, and competing in a scheduled competition which concludes with a culminating event involving the celebration of achievement and allocation of prizes. Students take on a number of roles during Sport Education including being coaches, team managers, players and referees. In addition to the roles that are directly related to their teams, students also serve on duty teams, act as first aid people, and help organise draws and publicity. In essence, Sport Education is a pedagogical model that seeks to empower students and to allow them to take responsibility for controlling and directing their own experiences (Siedentop et al., 2004).

The elements of being given meaningful responsibilities, along with long-term affiliation to a team suggest that Sport Education may well be a suitable context for teaching in combination with TPSR. When consideration is given to whether Sport Education will allow students the opportunity to achieve the five goals/levels of TPSR it can be seen that students involved in well designed Sport Education programmes have the opportunity to experience them all. Students are able to show respect for others; to make an effort to be involved; to initiate self-directed learning; and to care, both in their interactions with other students and by the roles that they choose to take within the class. The variation in ability and experience among team members, when combined with the group attempting to achieve a common purpose, offers a rich opportunity for students to practise both personal and social responsibilities.
In relation to the final goal, transfer of learning, it can be seen that much of the learning that occurs has the potential to be applied in other aspects of students' lives.

A number of similarities that support the potential for the two models to be merged have also been identified at a theoretical level. Hastie and Buchanan (2000) considered that they shared a common theory of learning in that both "draw from constructivist theory" (p. 26) which lead to the inclusion of active and student-centered learning pedagogies. Kirk (1998) in his discussion on the relevance of contemporary physical education identified Sport Education and TPSR as two emergent models that were attempting to prepare students for participation in their communities of practice.

It would appear then, that combining the two models would be both sensible and relatively unproblematic. The degree to which teachers do merge the models in practice is uncertain, however, as while there are anecdotal reports that this is occurring, there has been limited empirical examination of the situation to date.

In an attempt to gain an understanding of the situation in New Zealand schools, all secondary school physical education departments were surveyed about their use of TPSR (Gordon, Hodis, \& Thevenard, 2009). Of the 148 teachers who responded that they used TPSR in their teaching, $102(68.9 \%)$ reported that they had taught TPSR in combination with Sport Education. Teachers who taught the two models together were also asked to indicate how successful they felt the combination was on a scale of 0 (Very unsuccessful) to 9 (Very successful). The average response to this question was 7.27 which would suggest that, in New Zealand anyway, a large percentage of the teachers using TPSR considered that merging it with Sport Education was both a viable and successful option.

Despite the apparent congruence between TPSR and Sport Education it needs to be acknowledged that tensions can arise when the two are taught as a merged model. Hellison (Personal correspondence, March 20, 2009) expressed concern, at a philosophical level, that there was a fundamental conflict because essentially the two models were attempting to meet different purposes. Sport Education is about "promoting good sport in the culture ...[while] TPSR is about helping kids become better people". Hastie and Buchanan (2000) considered a major difference was that Hellison "placed the individual at the centre of his model [TPSR] ... Sport Education, however, focuses on sport, with individuals within a Sport Education season all contributing individually and collectively towards a positive sport experience for all" (p. 26).

At a practical level tensions exist within a merged model over the different ways in which games are used and by the emphasis placed on internal versus external sources of authority and control (Hastie \& Buchanan, 2000). Within TPSR, games are placed within an informal game structure and are used in a flexible way. There is strong encouragement for teachers using TPSR to modify the way the games are played whenever they consider that this will help meet the goals of the model. These changes are often generated by the students themselves in response to situations that arise within the lesson. If, for example, it 
appears that some players are being excluded in a basketball game, the game can be modified to require all players to touch the ball before a shot can be taken. Another example of a modification to normal practice is the encouragement of high skilled players to play soft defence when marking less able opponents (Hellison, 2003). Getting players to play in this way is intended to encourage empathy and to allow students to demonstrate caring in a practical way. The underpinning philosophy in TPSR in relation to games is that they are vehicles for learning and that modifications to the rules can occur at any suitable time. Any changes that occur are considered transient and they may be removed and/or reintroduced whenever the students or the teacher feels it is appropriate.

This fluidity in the ways that games are played contrasts strongly with what occurs in Sport Education. A formalised competition is an integral aspect of Sport Education with established draws identifying a schedule of games throughout the module. This schedule of games is published early in the season and leads towards a high profile culminating event (Siedentop, 1994). While this competitive structure appears to be inflexible it should be noted that there is room for some variance in the ways that the games are played. Where there is a range of abilities within the class, for example, it is suggested that graded competitions could be arranged where players of similar ability play each other. As a further refinement it is suggested that other changes can occur "by having the game be somewhat different in each of the competition levels" (Siedentop et al., 2004, p. 68). This means that the players in the A grade may play with a different size court or scoring rules than the teams in the D grade. While there may be some variations agreed to in Sport Education, the need to be fair to the players means that once the competition phase has begun the rules generally remain fixed.

The variations in the way the games are played in TPSR are not consistent with the expectations of an organised sporting competition and, if variations in the rules were to occur, this would take away from students the opportunity to experience what would be considered a normal sporting season. Conversely, if the ability to change rules to allow focus on outcomes specifically related to TPSR was removed, then this would disadvantage students in their learning around TPSR.

A second example that highlights the tension that can arise between the objectives of TPSR and Sport Education is the decision of whether to have games controlled by umpires and referees (Hastie \& Buchanan, 2000). If the TPSR philosophy is followed, then students would have the opportunity to play without referees, to allow them to develop the personal and social skills needed to play selfregulated competitive games. Teachers who are motivated by objectives aligned with TPSR are generally more interested in students developing internal control than in their learning to respond to, and value, forms of external control. For this reason it is common practice to ask students to call their own fouls and violations, and to resolve disputes among themselves without external adjudication. The use of the talking bench is an example of a pedagogical technique deliberately used to allow students to work through this resolution process (Hellison, 2003). Students in dispute temporarily leave the game and are required to sit together and to reach agreement on what the dispute was about, what each person's responsibility was in the situation, and to identify a way to resolve the problem that is acceptable to all. The intent of the talking bench is to create a powerful learning context to help in the development of personal and social responsibility, an opportunity lost if referees take control of the games and in effect solve disputes for the participants.

If the Sport Education philosophy is followed then the games will be controlled by student referees or umpires. To do this is to remain true to one of the basic premises of SE which is to:

Develop and apply knowledge about umpiring, refereeing and training. Every student will umpire or referee during each sport season ... Because all students referee or umpire in each season, the context is set for them to be more aware of how crucial good referees are to good competition and how difficult the tasks can be. (Siedentop et al., 2004, p. 12)

The decision on whether to have umpires and referees involved in games may initially appear to be of no great importance. What it does, however, is give a clear indication of which of the two models will be prioritised when conflicting requirements arise.

\section{Implications}

While Sport Education is only one of many contexts that can be chosen for the teaching of TPSR it can be argued that it has the potential to be a particularly powerful one in which to facilitate learning around personal and social responsibility. The pressure and perceived importance of competitive sports can be extremely useful in testing the depth of commitment to, and engagement with, the learning outcomes and beliefs associated with TPSR. The depth of empathy and caring that a student has is tested to a far greater degree, for example, when the opportunity to allow a weaker opponent to shoot unopposed occurs during a highly charged competitive game as opposed to when it occurs in a social one. The responses of players and their team-mates in these situations offer an invaluable contextual opportunity to stimulate discussion around the learning associated with TPSR during group discussions and individual reflection time.

The combining of Sport Education with TPSR appears to make intuitive sense for many teachers. The requirement for students in Sport Education to take responsibilities in a variety of ways suggests that there is a high level of congruence between the two models. The New Zealand survey showed that teachers are combining the models in their practice with almost $70 \%$ of the teachers who taught TPSR having taught the model in combination with Sport Education. While this survey was restricted to New Zealand it would not be unreasonable to assume that merging of the two models is also occurring in other countries in which both models are taught.

How the merged models are implemented in practice and what will actually occur when they are taught together is 
not certain. It would seem inevitable that when the two models are combined that there will be times when the requirements of one are in conflict with the requirements of the other. When this occurs the result will be that the outcomes relating to one model will be strengthened and conversely, the outcomes related to the other will be weakened. In Hastie and Buchanan's (2000) examination of a 26 lesson session of Xball they concluded that:

To summarise the experience, then, it could be stated that using the goal levels served to improve the performance of the players in the responsibility aspects of Sport Education. That is, the personal well-being aspects of TPSR served to improve the quality of the Sport Education season. This is a more accurate description than the alternative of Sport Education being used to selectively introduce the key phases of TPSR. (p. 34)

Hastie and Buchanan considered that the merging of Sport Education and TPSR led to a hybrid model that they named "Empowering Sport" (p. 34). Empowering Sport was described as "a sport-based model that foregrounded specific features of both Sport Education and TPSR [in which] the relative contribution of Sport Education and TPSR changed, depending on the stage of the season" (p. 34).

For teachers who are considering combining TPSR and Sport Education the strong suggestion is that they make a conscious decision to prioritise one of the two models rather than attempting to meet the goals of both. In other words, teachers should decide whether they are teaching TPSR, with Sport Education being used as context, or they are teaching a Sport Education unit which includes some aspects of TPSR. This is not an equal merging of the two models but a situation in which elements of one are used to strengthen the outcomes related to the prioritised model.

It is important that a firm decision is made as clarity and consistency of purpose will help focus learning around the prioritised model while still giving the opportunity of achieving a number of outcomes related to the other. This is a more favourable outcome than the alternative where neither model is consistently given priority. In this situation decision making can become reactive and inconsistent with a resulting weakening of learning for both models

What actually occurs when the two models are merged in physical education is at this stage under-researched and largely unknown. The New Zealand research identified that teachers generally considered that merging the models was successful, but it did not identify how they defined success. Was success measured in terms of outcomes related to TPSR or in outcomes related to Sport Education? Alternatively, were the teachers' measures of success more pragmatic and related to student behaviour and engagement? Whatever the reality is of teachers' and students' experiences of the merged model, it appears likely that teachers will continue to use it in their classrooms and that how it is implemented in practice will depend largely on the individual teacher's beliefs about what is important. It is for this reason that it is important that teachers consciously decide on what set of outcomes they wish to prioritise before they start their planning.

\section{References}

Gordon, B. (2007). An examination of an implementation of the responsibility model in a New Zealand secondary school physical education programme. Unpublished $\mathrm{PhD}$ Dissertation, Massey University, New Zealand.

Gordon, B., Hodis, F, \& Thevenard, 1. (Unpublished). An examination of the teaching of Teaching Personal and Socia Responsibility in New Zealand secondary school physical education programmes. Victoria University of Wellington

Hastie, P., \& Buchanan, A. (2000). Teaching responsibility through sport education: Prospects of a coalition. Research Quarterly For Exercise and Sport, $71(1), 25-38$.

Hellison, D. (2003). Teaching responsibility through physical activity. Campaign, IL: Human Kinetics.

Hellison, D., Cutforth, N., Kallusky, J., Martinek, T., Parker, M., \& Stichl, J. (2000). Youth development and physical activity. Champaign, IL: Human Kinetics.

Hellison, D., \& Martinek, T. (2006). Social and individual responsibility programs. In D. Kirk (Ed.), The handbook of physical education. Thousand Oaks, California: SAGE.

Siedentop, D. (1994). Sport education. Champaign, IL: Human Kinetics.

Siedentop, D. (2002). Sport education: A retrospective. Journal of Teaching in Physical Education, 21(4), 409-418.

Siedentop, D., Hastie, P., \& Van der Mars, H. (2004). Sport Education. Champaign, IL: Human Kinetics.

\section{Author's Note}

Barrie is a senior lecturer in health and physical education at Victoria University of Wellington in New Zealand. His research interests are based around the teaching of physical education in schools. He has a particular interest in the Teaching Personal and Social Responsibility Model and Teaching Games for Understanding.

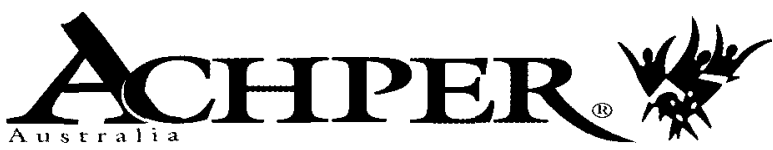

Australian Council for Health, Physical Education and Recreation

The Australian Council for Health, Physical Education and Recreation Inc. (ACHPER) is a leading professional, association representing professionals working in the fields of health, physical education, human movement studies, sport, recreation, dance and community fitness. It is a member based, not for profit organisation with a highly credible national profile.

The Mission of the Council is to promote active and healthy living for all Australians and particularly to support educators and its members in the study and of its areas of interest.

\section{To find out more about ACHPER go to our website www.achper.org.au.}


Copyright of Full Text rests with the original copyright owner and, except as permitted under the Copyright Act 1968, copying this copyright material is prohibited without the permission of the owner or its exclusive licensee or agent or by way of a license from Copyright Agency Limited. For information about such licences contact Copyright Agency Limited on (02) 93947600 (ph) or (02) 93947601 (fax) 